\begin{tabular}{c} 
Volume and Issues Obtainable at Center for Sustainability Research and Consultancy \\
Journal of Business and Social Review in Emerging Economies \\
ISSN: 2519-089X (E): 2519-0326 \\
Volume 5: No. 2, December 2019 \\
ᄃSRᄃ \\
Journal homepage: www.publishing.globalcsrc.org/jbsee \\
\hline
\end{tabular}

\title{
Future Time Orientation and Moral Self-image: An Analysis of Adolescents in Private and Government Schools in Punjab Pakistan
}

\author{
${ }^{1}$ Muhammad Rizwan, ${ }^{2}$ Xuehong Qi, ${ }^{3}$ Iram Naz, ${ }^{4}$ Shumaila Akram \\ ${ }^{1}$ School of Education Science, Nanjing Normal University, Nanjing, China: malikrizwansandila@ hotmail.com \\ ${ }^{2}$ School of Education Science, Nanjing Normal University, Nanjing, China \\ ${ }^{3}$ Department of Psychology, University of Gujrat, Pakistan \\ ${ }^{4}$ Department of Psychology, University of Gujrat, Pakistan
}

\begin{tabular}{l} 
ARTICLE DETAILS \\
\hline History \\
Revised format: November 2019 \\
Available Online: December 2019
\end{tabular}

\section{Keywords}

Future Time Orientation, Moral

Self-image, Government, Private

Schools, Gender

JEL Classification:

D99, I18, $I 19$

\section{ABSTRACT}

The purpose of the present research was to investigate future time orientation and moral self-image in the adolescents of government and private schools. A sample of 300 adolescents was studied from the government and private schools of Kharian, Pakistan by using simple random sampling technique. The construct of future time orientation was measured by using Time Orientation Scale (Zimbardo \& Boyd 1999) whereas moral self-image was measured by using Moral Self Image Scale (Jordan, Leliveld, \& Tenbrunsel, 2015). The data was analyzed by using simple regression and independent sample t-test. The results revealed that future time orientation was the significant predictor of moral-self-image $\left[\mathrm{R}^{2}=.168 ; \mathrm{F}(1,298)=60.103, \mathrm{p}<.01\right]$. Further, there was difference in the future time orientation of adolescents of government and private school $(\mathrm{t}$ $(298)=3.40, \mathrm{p}<.05)$ and difference in moral self-image was not significant $(\mathrm{t}(298)=1.02, \mathrm{p}>.05)$. Whereas on gender there was a nonsignificant difference persist in the future time orientation $(\mathrm{t}(298)=.62$, $\mathrm{p}>.05)$ and significant difference identified on moral self-image $(\mathrm{t}(298)=$ $-2.1, \mathrm{p}<.05)$. It was explored that future time orientation was the significant predicator of the moral self-image. Moreover, there was difference in the future time orientation of government and private school adolescents and no difference on the moral self-image. Moreover, no gender difference was established on future time orientation and a gender difference existed on the moral self-image.

(C) 2019 The authors, under a Creative Commons AttributionNonCommercial 4.0

Corresponding author's email address: malikrizwansandila@ hotmail.com

Recommended citation: Rizwan, M., Qi, X., Naz, I. and Akram, S., (2019). Future Time Orientation and Moral Self-image: An Analysis of Adolescents in Private and Government Schools in Punjab Pakistan. Journal of Business and Social Review in Emerging Economies, 5 (2), 359-366

DOI: $10.26710 /$ jbsee.v5i2.928

\section{Introduction}

Morality can be referred as a notion that explains what is right and what is wrong (Erikson \& Haraldsson, 2013) Jordan, Leliveld and Tenbrunsel (2015) evaluated that substantiation of unethical and disreputable behavior is well-known in society. Shalvi, Gino, Barkan, \& Ayal (2015) proposed that person's own perceptions about his morality or ethics is flexible and vibrant, and can affect the consequent behavior at 
any moment in time, situation and social factors may fluctuate person's view about moral self. Jordan, Leliveld and Tenbrunsel (2015) has investigated and proposed the concept of the moral self-image. They defined moral self-image as an individual's malleable and dynamic ethical self-concept and offer awareness into this pliability of moral self-image.

Every individual wants to view himself as a moral being (Monin \& Jordan, 2009) and take solid actions to continue this confidence when they act dishonestly (Barkan, Ayal, Gino, \& Ariely, 2012). Further, according to Jordan, Mullen, \& Murnighan (2011) when individual behave ethically, their self-concept strengthened and permitting him to reduce his consequent moral strivings and involve in immoral behaviors. Whereas, when person behave immorally, they pursue to support this self-concept by involving in moral behaviors. Moreover, if there was inconsistency among individual's perceived ideal moral self-image and actual moral self-image it leads to a vibrant and flexible awareness of individual's towards different moral self at any time (Moore \& Gino, 2013).

There are many factors that can affect the moral self-image, one of the important factor may be future time orientation. The time perspective shows how different human experiences are manipulated and organized into different temporal dimensions (Worrell \& Mello, 2007). The Zimbardo Time Perspective provides a quantifiable measure of time, which is represented as five dimensions like past positive, pastnegative, present-fatalistic, present-hedonistic, and future (Zimbardo \& Boyd, 1999). The future time orientation can be explained as a person's thinking style, strategies, drives, hopefulness and spirits about his or her future (Stoddard, Zimmerman, \& Bauermeister, 2011). Future orientation may be defined as a clear vision of the future and also have the knowledge of the impact of present actions on future results (Rothspan \& Read, 1996). The future orientation focuses on overarching personal values and abstract issues. The characteristics may include interest to responsibility, analytical decision making, risk taking and achievement of long-term goals (Holman \& Zimbardo, 2009).

It is of great significance to recognize the difficulties concerning to the adolescents (14-18 years) in schools. Adolescence is a face of person's life cycle that start from the onset of puberty in between the ages of 12-18 years (Dahl, 2006). Firstly, an individual encountered early adolescences stage that includes 10-13 years where a person develops more speedily with curious or anxiousness feelings about bodily changes. In the middle adolescence the age range is 14-17 years and person undergo change in the voice and the development of acne on the face. Additionally, adolescent involved in romance and sexual relationship with aggressive behavior for becoming independent. Finally, in the late adolescence the age is between 18-21 years. The physical changes are completed at that stage and adolescent's become more rational and close to family (Nienstein, Gordon, Katzman, \& Rosen, 2009). The changes in adolescent period creates a feeling of restlessness and confusion among them and change their way of perceiving the world (Casey, Jones, \& Hare, 2008). Further, the adolescent comprise of 1.2 billion of the world that is $16 \%$ of the world's population and the number will raise to $90 \%$ in 2050 specially in poor or middle income countries (World Health Organization, 2019). So it is important to see the problem pertaining to adolescents.

The main objective of the study was to investigate future time orientation as the predictor of moral selfimage in the adolescents of government and private schools. Research confirmed the that persons who were future time oriented as compare to present time oriented had high moral concern (Nordhall \& Agerström, 2013). Further, another study found that temporal distance or time perspective was connected with morality (Erikson \& Haraldsson, 2013).

Further, this study also seeks the difference in gender and school type (government and private school) on the future time orientation and moral self-image of adolescents. A study reported that school students were future oriented and girls were more future oriented as compare to boys (Mello \& Worrell, 2006). Further, the study will also seek out the difference in the future time orientation of adolescents of government and private schools. On account of difference in the moral self-image a study conducted in 
Pakistan compared gender and school type in relation to moral values. The results revealed that gender (boys or girls) and type of different schools (public or private) have main impact on the moral beliefs of children. The public school's students and boys had low morality whereas the students who belong to private school and girls had high morality (Javed, Kousar \& Khan, 2010).

\section{METHOD}

Cross-sectional survey research design was used in the present research.

\subsection{Participants}

The sample of 300 students was employed (150 Girls \& 150 Boys) in the research from kharian city of Punjab, Pakistan. The sample selected using simple random sampling from the 109 governments and 44 private schools in Kharian. 150 students taken from government and 150 from private schools. Among the 150 students 75 were boys and 75 girls from each setting.

\subsection{Measures}

The data was collected using a scale battery that was comprised of socio demographic form, Time Orientation Scale (Zimbardo \& Boyd 1999) and Moral Self Image Scale (Jordan, Leliveld, \& Tenbrunsel, 2015).

The socio-demographics form includes gender, age, education, birth order, number of siblings, family system, father's education, father's occupation, mother's education and family income etc. The Future Time Orientation was measured using Time Orientation Scale (Zimbardo \& Boyd 1999). There were three sub-scales (past, present and future) of the Time Orientation Scale but researcher used only Future Orientation sub-scale. It was consisted of 13 items with 5 point likert scale. The Moral Self Image Scale (Jordan, Leliveld, \& Tenbrunsel, 2015) measures and understanding the malleability of the moral self. In this scale researcher measured Moral Self Image by presenting nine traits perceived as prototypical of the ideally-moral person by using 9 point Likert scale. Researcher asked students to designate where they were relating to their ideal self on nine different traits.

\subsection{Procedure}

The data was collected from the adolescents of government and private school using simple random sampling technique. The aim and procedure of the research were finalized by the convener Department Research Review Committee (DRRC), University of Gujrat, Pakistan. The list of schools was taken from the Chief Executive officer (CEO). The data collection permission had been taken from institution and departments. Informed consent had been taken from respondent parents or guardian through school. In the inform consent, researcher fully described the purpose and all other important information related to research. In the consent form, researcher also guarantee the privacy and confidentiality of the provided information and right to with draw the research at any time. Before data collection, rapport was built with the respondents. After that the socio-demographic form, future time orientation scale and moral selfimage scale was filled out by the adolescents. The students were requested to read the statement and initiate a response that suits them. Both scales were used in the study after taking permissions from authors.

\subsection{Statistical Analysis}

The data of the study was analyzed by regression and independent sample t-test analysis. Regression is a technique which is use to predict relationship among variables when a change or variation in a dependent variable depends on a change or variation in independent variables. Simple regression analysis was used 
to see the predictive relationship of future time orientation on the morla self-image of adolescents of government and private's schools.

The independent sample t-test used to evaluate the difference in groups. It can compare the mean scores of the two different groups of conditions or people. In the current study the comparison of government and private school's adolescents were done on future time orientation and moral self-image. Further, the gender comparison of the two variables was also seen.

\section{Results}

Regression and independent sample $t$ test was used to analyzed future time orientation and moral selfimage of adolescents of private and government schools.

\section{Table 1}

Summary of regression analysis of Future Time Orientation as a predictor of Moral Self Image in Government and Private Schools Students (N =300)

\begin{tabular}{|l|l|l|l|l|l|}
\hline Variables & $\mathrm{R}$ & $\mathrm{R} 2$ & $\boldsymbol{\Delta} \mathrm{R} 2$ & $\mathrm{~F}$ & $\mathrm{P}$ \\
\hline Future Time Orientation & .410 & .168 & .165 & 60.103 & .000 \\
\hline Moral Self Image & & & & & \\
\hline
\end{tabular}

According to Table 1 future time orientation was the significant predictor of moral self-image $\left[\mathrm{R}^{2}=.168 ; \mathrm{F}\right.$ $(1,298)=60.103, \mathrm{p}<.01]$. The $16.8 \%$ of the variation in moral self-image is explained by future time orientation.

\section{Table 2}

Means and Standard Deviations of Government and Private Schools Students on Future Time Orientation and Moral Self-image $(\mathrm{N}=300)$

\begin{tabular}{|l|l|l|l|l|l|l|l|}
\hline & \multicolumn{2}{|l|}{ Government } & \multicolumn{2}{l|}{ Private } & & \\
& & & & & \\
\hline Variables Time & 52.00 & 5.76 & 49.47 & 7.01 & $3.40(298)$ & .001 & 0.405 \\
\hline $\begin{array}{l}\text { Future } \\
\text { Orientation }\end{array}$ & & & & & & \\
\hline Moral Self Image & 46.12 & 9.83 & 44.84 & 11.79 & $1.02(298)$ & .308 & 0.120 \\
\hline
\end{tabular}

Table 2 shown on future time orientation there was difference between the adolescents of government and private schools $(\mathrm{t}(298)=3.40, \mathrm{p}<.05)$. It means there was a difference in the future time orientation in the two groups. The difference was also evident from mean and standard deviation scores of Future Time Orientation in adolescents of government and private Schools. Further, in case of moral self-image the 
difference was insignificant $(\mathrm{t}(298)=1.02, \mathrm{p}>.05)$ whereas the mean and standard deviation scores indicated a difference in the moral self-image of government and private school's adolescents. Furthermore, the Cohen's d effect size indicated that future time orientation has approximately moderate effect size while moral self-image showed small effect size.

\section{Table 3}

Means and Standard Deviations of Boys and Girls on Future Time Orientation and Moral Self-image $(\mathrm{N}=300)$

\begin{tabular}{|l|l|l|l|l|l|l|l|}
\hline & \multicolumn{2}{|l|}{ Boys } & \multicolumn{2}{l|}{ Girls } & & \\
& & & & & \\
\hline Variables & $\mathrm{M}$ & SD & $\mathrm{M}$ & SD & $\mathrm{t}(\mathrm{df})$ & $\mathrm{p}$ & Cohen's d \\
\hline $\begin{array}{l}\text { Future } \\
\text { Orientation }\end{array}$ & 50.97 & 6.84 & 50.5 & 6.22 & $.62(298)$ & .53 & 0.06 \\
\hline Moral Self Image & 44.15 & 11.05 & 46.8 & 10.53 & $-2.1(298)$ & .03 & 0.25 \\
\hline
\end{tabular}

Table 3 indicated that there was no difference in the future time orientation of boys and girls $(\mathrm{t}(298)=$ $.62, \mathrm{p}>.05)$. The means and standard deviation scores also indicated no difference. Further, on moral selfimage there was a significant difference exist in the moral self-image of boys and girls ( $\mathrm{t}(298)=-2.1$, $\mathrm{p}<.05)$. The difference can also be seen in the mean and standard deviation scores. Further, Cohen's $d$ of the two variables indicated a small effect size especially on future time orientation the effect size is almost zero.

\section{Discussion}

The main objective of the study investigates future time orientation as the predictor moral self-image in adolescents of government and private school.

The findings of regression analysis established that future time orientation was the significant predictor of moral self-image $\left[\mathrm{R}^{2}=.168 ; \mathrm{F}(1,298)=60.103, \mathrm{p}<.01\right]$ in the adolescents of government and private schools with $16.8 \%$ explained variation. It was seen that positive future orientation can enhance student's functioning in school. It was also noted that student's school setting boost their future beliefs that can be done through progressive student-teacher relationship, educational motivation and accomplishment (Alm, Låftman, Sandahl \& Modin, 2019). Previous studies confirmed the findings of the current research as the time perspectives play a vital role in determining the moral concerns (Agerström \& Björklund, 2009) and (Eyal, Liberman \& Trope, 2008).

Another, sub-objective of the study was to find out the difference of future time orientation and moral self-image in the adolescents of government and private schools. It was identified that there was significant difference in the future time orientation $(\mathrm{t}(298)=3.40, \mathrm{p}<.05)$ and government school's adolescents showed better future time orientation. Previous research established the fact that students in schools were future oriented (Mello \& Worrell, 2006). Further, a non-significant difference $(\mathrm{t}(298)=$ $1.02, \mathrm{p}>.05)$ was exposed on moral self-image. The result was unlike literature that confirmed that school type influenced the morality and public school's students lack morality (Javed, Kousar \& Khan, 2010).

Lastly, another sub-objective of study explores the gender difference in the future time orientation and moral self-image. Results indicated that there was no gender difference in the future time orientation ( $t$ $(298)=.62, \mathrm{p}>.05)$ and the literature was opposite to the current study findings that confirmed that girls 
were more future oriented as compare to boys (Mello \& Worrell, 2006). Furthermore, there was a significant gender difference revealed in the moral self-image ( $t(298)=-2.1, p<.05)$ with better moral concerns in females. The literature was in line with the result that identified gender difference in moral self-concept of person (Chui \& Wong, 2016). Another, study stated that females had better moral self (Zhang, 2010) and same was evident in the present research. There was literature available that was inconsistent with current study finds and showed that girls had more present time orientation (Zimbardo, Keough, \& Boyd, 1997).

\section{Conclusion}

It was concluded that future time orientation was the significant predicator of the moral self-image in adolescents. Further, there was difference in the future time orientation of government and private school adolescents with better future time orientation of government school adolescents. In case of moral selfimage, there was no difference in the government and private school adolescents. Furthermore, on gender no difference was found on future time orientation. Whereas on gender there was difference in the moral self-image and girls and girls had better moral self-image.

The study identified the importance of future time orientation in educational settings. It indicated that time perspective is an important area to be investigated by educationists and researchers in facilitating the education. Further, this study surely helps to aware the role of moral development of the children in the school system in Pakistan.

\section{References}

Agerström, J., \& Björklund, F. (2009b). Moral Concerns Are Greater for Temporally Distant Events and Are Moderated by Value Strength. Social Cognition, 27 (2), 261-282.

Alm, S., Låftman, S.B., Sandahl, J., \& Modin, B. (2019). School effectiveness and students' future orientation: A multilevel analysis of upper secondary schools in Stockholm, Sweden. Journal of Adolescence, 70, 62-73.

Barkan, R., Ayal, S., Gino, F., \& Ariely, D. (2012). The pot calling the kettle black: distancing response to ethical dissonance. Journal of Experimental Psychology: General, 141, 757-773. doi:10.1037/a0027588

Casey, B.J., Jones, R.M \& Hare, T.A. (2008). The Adolescent Brain. Annals of New York Academy of Science, 1124(1), 111-126.

Chui, W.H., \& Wong, M.Y. (2016). Gender differences in happiness and life satisfaction among adolescents in Hong Kong: Relationships and self-concept. Social Indicators Research, 125, 1035 1051.

Dahl, R.E. (2006). Adolescents Brain Development: A Period of Vulnerabilities and Opportunities. Key Note Address. Annals of the New York Academy of Science, 1021(1), 1-22.

Erikson, M., \& Haraldsson, E. L.G. (2013). Time, Abstraction and Morality. Unpublished Basehor's dissertation, Faculty of Health and Life Sciences, Linnaeus University, Kalmar-Sweden.

Eyal, T., Liberman, N., \& Trope, Y. (2008). Judging near and distant virtue and vice. Journal of Experimental Social Psychology, 44, 1204-1209.

Holman, E.A., \& Zimbardo, P. (2009). The Social Language of Time: The Time Perspective Social Network Connection. Basic and Applied Social Psychology, 31(2), 136-147.

Javed, A., Kousar, R., \& Khan, N. (2010). Effects of school system and gender on moral values and forgiveness in Pakistani school children. Malaysian Online Journal of Educational Science, 2(4), 13-24.

Jordan, J., Leliveld, M. C., \& Tenbrunsel, A. E. (2015). The Moral Self-Image Scale: Measuring and Understanding the Malleability of the Moral Self. Frontiers in Psychology, 6. doi: 10.3389/fpsyg.2015.01878

Jordan, J., Mullen, E., \& Murnighan, J.K. (2011). Striving for the moral self: the effects of recalling past moral actions on future moral behavior. Personality and Social Psychology Bulletin, 37,701713.doi:10.1177/0146167211400208 
Mello, Z.R., \& Worrell, F.C. (2006). The Relationship of Time Perspective to Age, Gender, and Academic Achievement Among Academically Talented Adolescents. Journal for the Education of the Gifted, 29(3), 271-289.

Monin, B., and Jordan, A.H. (2009). "The dynamic moral self: a social psychological perspective," in Personality, Identity, and Character: Explorations in Moral Psychology, eds D. Narvaez and D.K .Lapsley (New York, NY: Cambridge University Press),341-354.

Moore, C., \& Gino, F. (2013). Ethically a drift: how others pull our moral compass from true north, and how we can fix it. Research in Organizational Behavior, 33, 53-77.doi: 10.1016/j.riob.2013.08.001

Neinstein, L.S., Gordon, C.M., Katzman, D.K., \& Rosen, D.S. (2009). Handbook of Adolescent Health Care. Philadelphia, PA: Lipppincott, Williams \& Wilkins.

Nordhall, O., \& Agerström, J. (2013). Future-oriented people show stronger moral concerns. Current research in Social Psychology, 21(6), 52-63

Rothspan, S., \& Read, S. J. (1996). Present versus future time perspective and HIV risk among heterosexual college students. Healthy Psychology, 15, 131-134. http://dx.doi.org/10.1037/02786133.15.2.131

Shalvi, S., Gino, F., Barkan, R., \& Ayal, S. (2015). Self- serving justifications doing wrong and feeling moral. Current Directions in Psychological Science, 24,125-130.doi: 10.1177/0963721414553264

Stoddard, S.A., Zimmerman, M.A., \& Bauermeister, J.A. (2011). Thinking about the future as a way to succeed in the present. A longitudinal study of future orientation and violent behaviors among African American youth. American Journal of Community Psychology, 48 (3-4), 238-246

World Health Organization (2019). Achieving universal health coverage for the world's 1.2 billion adolescents.

Retrieved

from https://www.who.int/maternal_child_adolescent/adolescence/universal-health-coverage/en/

Worrell, F. C., \& Mello, Z. R. (2007). Reliability and validity of Zimbardo Time Perspective Inventory scores in academically talented adolescents. Educational and Psychological Measurement, 67, 487-504.

Zhang X (2010) The study of university students' self-concept. Journal of Studies in International Education, 3, 83-86.

Zimbardo, P. G., Keough, K. A., \& Boyd, J. N. (1997). Present time perspective as a predictor of risk driving. Personality and Individual Difference, 23, 1007-1023.

Zimbardo, P.G., \& Boyd, J.N. (1999). Putting Time in Perspective: A Valid, Reliable Individual Differences Metric. Journal of Personality and Social Psychology, 77 (6), 1271-1288. 
